\title{
The bioguided fractionation and pharmacological activity of an endemic Salix canariensis species
}

\author{
SANDRA DÉVORA GUTIÉRREZ* \\ SUSANA ABDALA KURI \\ DOMINGO MARTÍN-HERRERA

\section{Unidad de Farmacología y} \\ Farmacognosia \\ Sección de Farmacia, Facultad de \\ Ciencias de La Salud \\ Universidad de La Laguna \\ 38071, La Laguna, Tenerife, Canary \\ Islands, Spain
}

Accepted December 28, 2016

Published online January 16, 2017

\begin{abstract}
The present study was designed to confirm the wide traditional use of treating pain with Salix canariensis, an endemic species of the Macaronesian region. The active compounds were identified. Pharmacological activities were explored in experimental animals by acetic acid-induced writhing, formalin and Levy's tests, and bioactive compounds were identified after a bio-guided fractionation of the most active organic extract. S. canariensis extract, orally administrated at different doses, led to a significant reduction in writhing, caused a moderate decrease of formalin-induced pain and revealed an excellent dose-dependent anti-inflammatory effect. Bioassay-guided fractionation of the ethyl acetate extract suggested the possible presence of pentacyclic triterpenes from oleanane and ursane series. These findings allow the conclusion that $S$. canariensis exerts analgesic and anti-inflammatory activities, documenting its traditional use in the treatment of pain and inflammatory diseases.
\end{abstract}

Keywords: Salix canariensis, analgesic activity, anti-inflammatory activity, bioassay fractionation, pentacyclic triterpenes, ursanes, oleananes

Ancient civilizations have traditionally used herbal remedies to treat various conditions, willow tree from the genus Salix being one of them. Willow tree belongs to the Salicaceae family and records of its medicinal use go back about 6000 years (1). The importance of this tree's anti-inflammatory, anti-rheumatic, antipyretic and analgesic properties to treat fever and pain has been well demonstrated.

Salix bark is a rich and inexpensive source of phenolic glycosides, flavonoids, condensed tannins and polyphenols (2). Salicylates (expressed as salicin) are found in all members of the Salix genus with S. daphnoides, S. fragilis and S. purpurea providing the highest yield (3). The abovementioned constituents are reported to possess, among others, antinociceptive, anti-inflammatory and antipyretic activities (4).

\footnotetext{
*Correspondence; e-mail: sabdala@ull.es
} 
Salix fragilis and S. canariensis are the two species of the Salix genus found in the Canary Islands. The former was introduced to the islands and the latter is endemic to the Macaronesian region, which includes Madeira and the Canary Islands. Ethno-botanical evidence indicates that the hot water infusion of the branches, leaves, flowers and barks of Salix canariensis, popularly known in the Canary Islands as "Sauce", principally contains tannins and phenolic glycosides such as salicin, and is widely used in folk medicine to treat pain disorders (5). The present study represents the first research into the activities of several extracts of $S$. canariensis in order to corroborate the widespread traditional use of this species and to identify the potentially most active compounds in animal models.

\section{EXPERIMENTAL}

\section{Plant material}

Branches, leaves, flowers and barks of S. canariensis were collected in the Los Tilos ravine of La Palma, Canary Islands (altitude 475 meters above sea level), were identified (Pedro Pérez de Paz, Department of Plant Biology, University of La Laguna, Tenerife, Spain) and voucher specimens were deposited.

\section{Extract preparation}

Collected aerial parts of $S$. canariensis were oven dried at $40{ }^{\circ} \mathrm{C}$ for four days and powdered in a mechanical mill. The aqueous crude extract was prepared by adding distilled water $(1: 10, m / V)$ twice at $100{ }^{\circ} \mathrm{C}$ for $1 \mathrm{~h}$, as described by Dévora et al. (6) with slight modifications. Aqueous extracts were then pooled, lyophilized to obtain a powder (yield $4.8 \%$ ) and stored. The lyophilizate was dissolved in distilled water and tested at doses of 52.5, 70.0 and $105.0 \mathrm{mg} \mathrm{kg}^{-1} \mathrm{bm}$.

All S. canariensis extracts and fractions, as well as $3 \%$ Tween 80 used as a negative control and NSAID reference drugs were administered orally. Acetic acid and morphine were administered intraperitoneally (i.p.), while formalin and carrageenan were given subcutaneously (s.c.).

\section{Fractionation of the ethyl acetate extract}

Fractionation of the plant extract was bio-guided by the inhibitory activity of the different extracts and fractions against pain produced by acetic acid and, after each purification step, the most active fractions were selected to continue isolation of active compounds. Dried powdered plant material was submitted to continuous extraction in four Soxhlet extractors for 7 days using organic solvents of increasing polarity: hexane (Scharlau, Spain), dichloromethane (99.9\%, Scharlau), ethyl acetate (99.5\%, Merck, Germany) and methanol (99.8 \%, Scharlau). The respective yields were 2.5, 4.7, 6.0 and $25.4 \%$. The solvents were then eliminated by vacuum distillation in a rotary vacuum evaporator (Büchler Corp., USA). The most active, ethyl acetate, extract was then submitted to further fractionation (Scheme 1). After chromatography on fine silica gel (0.063-0.200 nm diameter, Macherey-Nagel, Spain) with hexane/EtOAc of increasing polarity (chromatography A), the obtained fractions were concentrated in vacuum. The fractions with similar $R_{\mathrm{f}}$ values in 
TLC were grouped into 6 fractions (A1-A6). The most active one against acetic acid-induced writhing (A5) was subjected twice to Sephadex gel chromatography (chromatography B) to obtain four new fractions, which were also assayed by the acetic acid-induced writhing test. Another chromatography on silica gel with dichloromethane (DCM)/acetone of increasing polarity (chromatography $C$ ) was performed with the most active fractions (B1+B2) to obtain further 6 fractions. These fractions were joined according to their $R_{\mathrm{f}}$. Two out of 6 fractions ( $\mathrm{C} 3$ and $\mathrm{C} 4$ ) were submitted to further purification by preparative TLC (hexane/dioxane $30 \%$, Scharlau) (chromatography D). Three residues were obtained (D1D3) after TLC analysis.

The hexane, dichloromethane, ethyl acetate and methanol extracts and fractions tested in the acetic acid-induced writhing test were assayed at a dose of $50 \mathrm{mg} \mathrm{kg}^{-1} \mathrm{bm}$.

\section{Animals}

Animals (male and female Swiss mice) were obtained from the Central Animal House of La Laguna University (Tenerife, Spain) and their management and care were conducted in accordance with the Directive 2010/63/EU concerning the protection of animals used for scientific purposes. Approval by the Ethical Committee for Animal Research of La Laguna University was obtained. The animals were divided into groups of 5 or 10 per dose for the different studies.

\section{Pharmacological tests}

A study of acute toxicity was performed as described by Abdala et al. (7) before the different tests.

Acetic acid-induced writhing test. - Analgesic activity of the plant extracts was studied through the reduction of acetic acid-induced writhing in mice (8). The animals were given an aqueous or organic extract or fraction, positive control ibuprofen $\left(75 \mathrm{mg} \mathrm{kg}^{-1} \mathrm{bm}\right.$, Sigma, Spain) and negative control Tween 80 (3\%, Ferosa, Spain). Forty-five minutes later, they were administered $1 \%$ acetic acid $\left(10 \mathrm{~mL} \mathrm{~kg}^{-1} \mathrm{bm}\right.$, Sigma). The number of abdominal constrictions was counted for $20 \mathrm{~min}$ thereafter and the percent inhibition was calculated.

Formalin test. - The method used was similar to that described by Dévora et al. (6). Twenty $\mu \mathrm{L}$ of $2.5 \%$ formaldehyde in saline (formaldehyde $36.5 \%$ solution, Scharlau) was injected into the right hind paw of the mice one hour after oral administration of the aqueous extract, NSAID control indomethacin $\left(20 \mathrm{mg} \mathrm{kg}^{-1} \mathrm{bm}\right.$, Sigma) or negative control Tween 80 , and 30 minutes after opioid control morphine $\left(10 \mathrm{mg} \mathrm{kg}^{-1} \mathrm{bm}\right.$, Braun Medical S.A., Spain). The number of shakes in the early phase ( $0-5 \mathrm{~min})$ and the time in seconds the mice spent licking or biting the injected paw or leg in the late phase (15-30 $\mathrm{min}$ ) after formalin injection was recorded and was taken as an indicator of pain response. The percent inhibition of pain response was calculated.

Anti-inflammatory activity: Levy's test. - Mice were pretreated with the aqueous extract, Tween 80 and ibuprofen at the same doses as in the acetic acid-induced writhing test. After thirty minutes, edema was induced by injection of $25 \mu \mathrm{L}$ of carrageenan (Sigma) in saline, according to Abdala et al. (7). Paw thickness was measured with a caliper at 0,2 and $4 \mathrm{~h}$ after carrageenan injection. The difference between the initial and final paw thickness of each animal gave the edema value. 
S. Dévora Gutiérrez et al.: The bioguided fractionation and pharmacological activity of an endemic Salix canariensis species, Acta Pharm. 67 (2017) 265-273.

\section{Statistical analysis}

Results are expressed as mean \pm standard error of the mean. Results were analyzed using one-way analysis of variance (ANOVA) followed by Dunnett's multiple test comparison using the SPSS version 16. The significance level was set at $p<0.05$.

\section{RESULTS AND DISCUSSION}

First, the effect of S. canariensis on peripheral nociception was evaluated using the acetic acid-induced writhing in mice. As can be seen in Table I, three doses of aqueous extract exerted a significant dose-dependent reduction in the number of writhing episodes induced by acetic acid when compared to the negative control. Pain reduction caused by the doses of 70.0 and $105.0 \mathrm{mg} \mathrm{kg}^{-1} \mathrm{bm}$ was 92.1 and $99.1 \%(p<0.001)$, resp. It is known that abdominal constrictions provoked by acetic acid injection are associated with peripheral inflammation and are believed to be mediated by an increase of prostaglandins, serotonin and histamine in peritoneal fluids (9). It is therefore possible that the analgesic effect of $S$. canariensis may be due to the reduction of these inflammation mediators.

The formalin test was used since the acetic acid-induced writhing test is not able to distinguish whether the analgesic effect of this plant occurs at the central or peripheral level. Injection of formalin has been reported to produce a distinct biphasic nociceptive response. The first phase ( 0 to $5 \mathrm{~min}$ ) results from direct stimulation of nociceptors. The second phase (15 to $30 \mathrm{~min}$ ) is thought to be an inflammatory response with associated inflammatory pain, which is a process in which several inflammatory mediators are believed to be involved, including histamine, serotonin, prostaglandins and bradykinin (10). In this study, the inhibitory effects of $S$. canariensis extracts were more marked in the second phase, suppressing the pain in a dose-dependent manner, by 23.2, 32.5 and $42.1 \%$ $(p<0.05)$, resp. (Table I). The results obtained in the first phase of the assay could suggest a slight central action, especially of the two highest doses, which reported similar percentages of analgesia (21.6 and $25.6 \%$ ). Regarding the drugs used as the positive control, indomethacin mainly inhibited the second phase by $85.0 \%(p<0.001)$ and morphine did so in both phases by $53.8 \%(p<0.01)$ and $96.1 \%(p<0.001)$, resp. These results are in agreement with the literature, which establishes that centrally acting drugs inhibit both phases of pain, while peripheral acting drugs mainly inhibit the second phase (11). Therefore, the results herein point to a predominantly peripheral action of $S$. canariensis.

In order to additionally confirm peripheral acute anti-inflammatory activity, effects of the $S$. canariensis aqueous extract were evaluated in mice using a carrageenan-induced paw edema model (Table I). In the aforementioned test, administration of S. canariensis extracts caused a dose-dependent effect at 2 and 4 hours post carrageenan injection. The strongest effects were obtained in the first phase. The values of $75.2(p<0.001)$ and $78.2 \%(p<0.001)$, resp., compared to the control group, were recorded with doses of 70.0 and $105.0 \mathrm{mg} \mathrm{kg}^{-1}$ $\mathrm{bm}$. The above pharmacological property may be attributable to a possible molecular mechanism, similar to that of ibuprofen, of effectively decreasing the production of the pro-inflammatory mediators and the expression of COX-2 (12).

Promising results obtained with the aqueous extract were the reason for identifying which of its bioactive compounds were responsible for the abovementioned activities. 
S. Dévora Gutiérrez et al.: The bioguided fractionation and pharmacological activity of an endemic Salix canariensis species, Acta Pharm. 67 (2017) 265-273.

Table I. Effect of the aqueous extract of Salix canariensis on the acetic acid-writhing test, formalin test and carrageenan-induced edema in mice

\begin{tabular}{|c|c|c|c|c|c|c|}
\hline \multirow{3}{*}{ Group } & \multirow{3}{*}{$\begin{array}{c}\text { Dose } \\
\left(\mathrm{mg} \mathrm{kg}^{-1}\right. \\
\text { p.o. })\end{array}$} & \multicolumn{5}{|c|}{ Test } \\
\hline & & \multirow{2}{*}{$\begin{array}{l}\text { Acetic } \\
\text { acid-writh- } \\
\text { ing test }\end{array}$} & \multicolumn{2}{|c|}{ Formalin test } & \multicolumn{2}{|c|}{ Carrageenan test } \\
\hline & & & $1^{\text {st }}$ phase & $2^{\text {nd }}$ phase & $2 \mathrm{~h}$ & $4 \mathrm{~h}$ \\
\hline & & $\begin{array}{l}X_{\mathrm{ST}} \pm \mathrm{SEM}^{\mathrm{a}} \\
\text { (inhib., \%) }\end{array}$ & $\begin{array}{c}X_{1 \text { st PHASE }} \pm \text { SEM }^{\text {a }} \\
\text { (inhib., \%) }\end{array}$ & $\begin{array}{c}X_{\text {2nd PHASE }} \pm \text { SEM }^{\text {a }} \\
\text { (inhib., } \%)\end{array}$ & $\begin{array}{l}X_{2 h} \pm S M^{a} \\
\text { (inhib., } \% \text { ) }\end{array}$ & $\begin{array}{l}X_{4 h} \pm S E^{a} \\
\text { (inhib., \%) }\end{array}$ \\
\hline $\begin{array}{c}\text { Negative } \\
\text { control } \\
\text { (3\% Tween } 80)\end{array}$ & - & $22.87 \pm 2.29$ & $23.29 \pm 1.20$ & $325.75 \pm 35.29$ & $1.33 \pm 0.24$ & $1.40 \pm 0.15$ \\
\hline Ibuprofen & 75 & $\begin{array}{c}4.75 \pm 4.11^{* *} \\
(79.2)\end{array}$ & n.a. & n.a. & $\begin{array}{c}0.40 \pm 0.11^{* *} \\
(69.9)\end{array}$ & $\begin{array}{c}0.65 \pm 0.10^{* *} \\
(53.6)\end{array}$ \\
\hline Morphine & 10 i.p. & n.a. & $\begin{array}{c}10.75 \pm 2.87^{* *} \\
(53.8)\end{array}$ & $\begin{array}{c}12.75 \pm 5.45^{* * *} \\
(96.1)\end{array}$ & n.a. & n.a. \\
\hline $\begin{array}{l}\text { Indo- } \\
\text { methacin }\end{array}$ & 20 & n.a. & $\begin{array}{c}16.64 \pm 2.87 \\
(28.6)\end{array}$ & $\begin{array}{c}48.94 \pm 5.45^{* * *} \\
(85.0)\end{array}$ & n.a. & n.a. \\
\hline $\mathrm{AE}$ & 52.5 & $\begin{array}{c}13.00 \pm 5.72 \\
(43.2)\end{array}$ & $\begin{array}{c}20.50 \pm 10.69 \\
(12.0)\end{array}$ & $\begin{array}{c}250.25 \pm 43.70 \\
(23.2)\end{array}$ & $\begin{array}{c}0.70 \pm 0.12^{*} \\
(47.4)\end{array}$ & $\begin{array}{c}0.90 \pm 0.10^{*} \\
(35.7)\end{array}$ \\
\hline $\mathrm{AE}$ & 70 & $\begin{array}{c}1.80 \pm 1.36^{* * *} \\
(92.1)\end{array}$ & $\begin{array}{c}18.25 \pm 6.75 \\
(21.6)\end{array}$ & $\begin{array}{c}219.75 \pm 72.03 \\
(32.5)\end{array}$ & $\begin{array}{c}0.33 \pm 0.12^{* * *} \\
(75.2)\end{array}$ & $\begin{array}{c}0.83 \pm 0.03^{*} \\
(40.7)\end{array}$ \\
\hline $\mathrm{AE}$ & 105 & $\begin{array}{c}0.20 \pm 0.20^{* * *} \\
(99.1)\end{array}$ & $\begin{array}{c}17.34 \pm 5.34 \\
(25.6)\end{array}$ & $\begin{array}{c}188.59 \pm 64.29^{*} \\
(42.1)\end{array}$ & $\begin{array}{c}0.29 \pm 0.10^{* * *} \\
(78.2)\end{array}$ & $\begin{array}{c}0.77 \pm 0.09^{* *} \\
(45.0)\end{array}$ \\
\hline
\end{tabular}

$\mathrm{AE}$ - aqueous extract, n.a. - not applied, $X_{\mathrm{ST}}$ - number of constrictions; $X_{1 \text { st PHASE }}-$ number of shakes of the formalin injected paw; $X_{2 \text { nd PHASE }}-$ time (s) that the mouse licks its injected paw; $X_{2 h}, X_{4 h}$ - difference in thickness of the injected paw after 2 and $4 \mathrm{~h}$, respectively.

Statistically significant difference compared to the control group: ${ }^{*} p<0.05 ;{ }^{* *} p<0.01 ;{ }^{* *} p<0.001$.

a $n=10$

Thus, the plant was subjected to a bioassay-guided fractionation, using the acetic acid-induced writing test as the indicator of activity. Prior to fractionation, four organic extracts of increasing polarity were prepared and tested. The most active extract was fractionated in order to isolate and identify the potential analgesic and anti-inflammatory compounds in S. canariensis.

As observed in Fig. 1, dichloromethane, ethyl acetate and methanol extracts produced marked inhibition of the acetic acid-induced abdominal constrictions compared to the negative control. Ethyl acetate extract was the most potent extract $(59.6 \%, p<0.05)$ in pain reduction and was therefore selected for further fractionation (Scheme 1). 
S. Dévora Gutiérrez et al.: The bioguided fractionation and pharmacological activity of an endemic Salix canariensis species, Acta Pharm. 67 (2017) 265-273.

Table II. Effect of Salix canariensis most active fractions on acetic acid-induced writhing in mice

\begin{tabular}{ccc}
\hline Group & Dose $\left(\mathrm{mg} \mathrm{kg}^{-1}\right.$ p.o. $)$ & $\mathrm{X}_{\mathrm{ST}}$ (inhibition, \%) \\
\hline $\begin{array}{c}\text { Negative control } \\
(3 \% \text { Tween } 80)\end{array}$ & - & $34.96 \pm 4.71$ \\
Ibuprofen & 75 & $(0.0)$ \\
A5 fraction & 50 & $3.90 \pm 1.10^{* * *}$ \\
& & $(88.8)$ \\
B1 fraction & 50 & $12.75 \pm 1.44^{* *}$ \\
B2 fraction & & $(63.5)$ \\
& 50 & $\left(49.75 \pm 2.84^{* *}\right.$ \\
\end{tabular}

$\mathrm{X}_{\mathrm{ST}}$ - number of constrictions

Mean \pm SEM, $n=10$

Statistically significant difference compared to the control group: ${ }^{*} p<0.05 ;{ }^{* *} p<0.01$;

*** $p<0.001$.

As can be seen in Table II, A5 was the most active analgesic fraction $(63.5 \% ; p<0.01)$ and was subjected to further fractionation. The two most active analgesic fractions, B1 and B2, reduced pain in the acetic acid-induced writhing test by $49.2(p<0.01)$ and $42.8 \%(p<0.05)$, resp., and were fractionated again. Two of the 6 fractions (C3 and C4) were submitted to further purification by preparative TLC, giving three residues that appeared to contain a mixture of pentacyclic triterpenes of oleanane and ursane type. The latter were identified by ${ }^{1} \mathrm{H}$ NMR.

Pentacyclic triterpenes are widely distributed in the plant kingdom and possess a wide range of pharmacologic and health promoting properties. Molecules with a skeleton of oleanane and ursane seem to be responsible, among others, for anti-inflammatory activity of a variety of medicinal plants through inhibition of enzymes involved in the production of eicosanoids, such as cyclooxygenase and phospholipase A2, which impede the release of cytokines, histamine and serotonin (13). However, they have never been described in the Salix genus.

Summing up the results obtained with acetic acid-induced writhing, it could be concluded that the original crude polar extracts (aqueous and methanol extracts) also produced an interesting analgesic activity, suggesting the presence of other polar compounds in the plant that could participate by exerting synergistic effects. Preliminary analysis of S. canariensis has shown the presence of salicylic derivatives, flavonoids and tannins (5). Available literature also describes clearly the role of these phytochemicals in the treatment of inflammation and associated problems, indicating that the phenolic compounds exert their analgesic and anti-inflammatory activities because of their influence on the metabolism of arachidonic acid and histamine release. Such metabolites seem to inhibit lysosomal enzyme secretion and arachidonic acid release from membranes by inhibiting lipoxygenase, COX, and phospholipase A2 $(14,15)$. Thus, it is possible that the analgesic and anti-inflammatory effects of the $S$. canariensis aqueous extract are also based on the pres- 


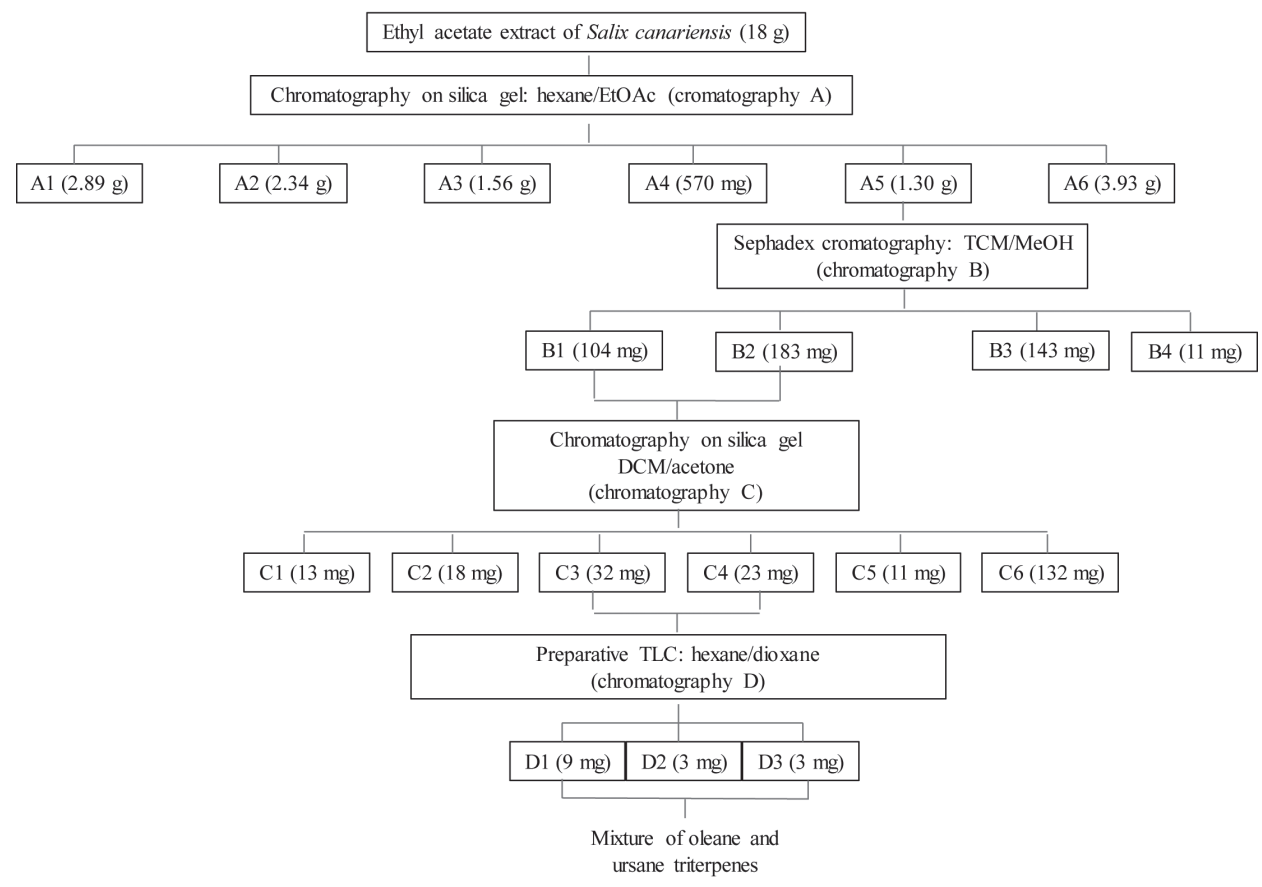

Scheme 1. Bioassay-guided fractionation of the ethyl acetate extract of Salix canariensis.

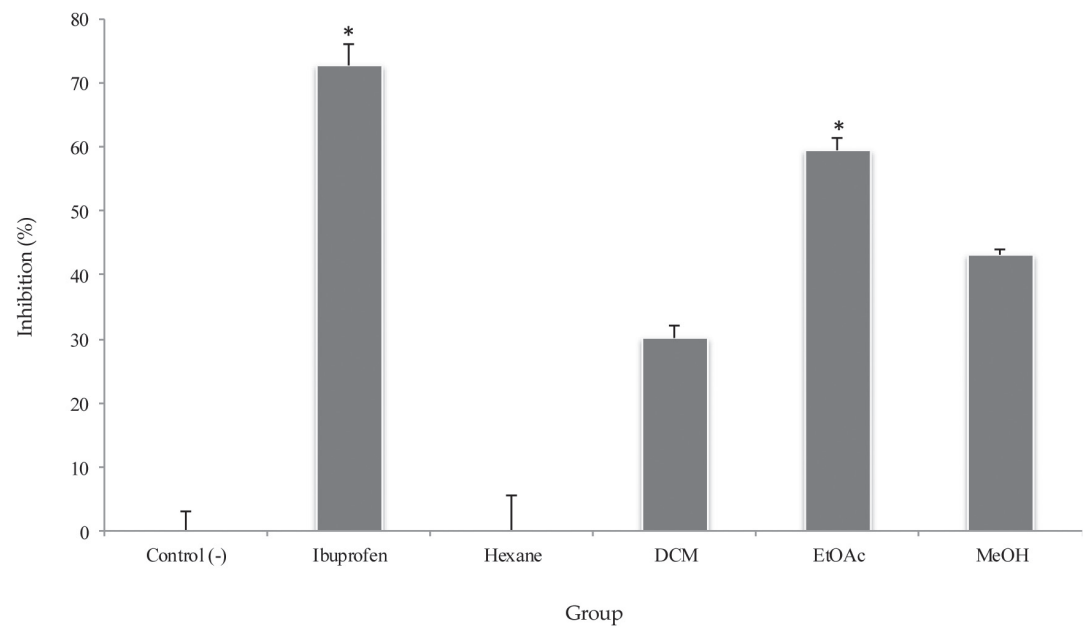

Fig. 1. Effects of hexane, dichloromethane, ethyl acetate and methanol extracts $\left(50 \mathrm{mg}^{\mathrm{kg}}{ }^{-1}\right)$ of Salix canariensis on acetic acid-induced writhing in mice and positive and negative controls (mean $\pm \mathrm{SEM}, n=5$ ). Statistically significant difference compared to the control group: ${ }^{*} p<0.05$ 
ence of these active polar principles. Therefore, the phenolic compounds present in this plant may be responsible, in addition to the pentacyclic triterpenes identified for the first time in this species, for the anti-inflammatory and analgesic activities observed in $S$. canariensis.

On the other hand, an acute toxicity test was performed on the aqueous extract as taken in folk medicine. Its administration up to a $5.0 \mathrm{~g} \mathrm{~kg}^{-1} \mathrm{bm}$ dose has been proven to be safe, since no signs of toxicity were observed in the animals.

\section{CONCLUSIONS}

In conclusion, S. canariensis extracts exhibited significant analgesic and anti-inflammatory activities, scientifically validating the traditional use of the plant in the treatment of pain and inflammation. These activities seem to be due to the presence of phenolic compounds and pentacyclic triterpenes in the plant, which may act more synergistically than individually. More studies are needed to provide a better insight into the mechanism of these pharmacological actions.

Acknowledgements. - This work was supported by a Grant from Consejería de Educación, Cultura y Deportes del Gobierno de Canarias. The authors thank Dr. Pedro Pérez de Paz for identification of the plant.

\section{REFERENCES}

1. J. G. Mahdi, Medicinal potential of willow: A chemical perspective of aspirin discovery, J. Saudi Chem. Soc. 14 (2010) 317-322; DOI: 10.1016/j.jscs.2010.04.010.

2. A. Nahrstedt, M. Schmidt, R. Jaggi, J. Metz and M. T. Khayyal, Willow bark extract: the contribution of polyphenols to the overall effect, Wiener Med. Wochenschr. 157 (2007) 348-351; DOI: 10.1007/ s10354-007-0437-3.

3. B. Meier, O. Sticher and R. Julkunen-Tiitto, Pharmaceutical aspects of the use of willows in herbal remedies, Planta Med. 54 (1988) 559-560; DOI: 10.1055/s-2006-962554.

4. S. Sharma, D. Sahu, H. R. Das and D. Sharma, Amelioration of collagen-induced arthritis by Salix nigra bark extract via suppression of pro-inflammatory cytokines and oxidative stress, Food Chem. Toxicol. 49 (2011) 3395-3406; DOI: 10.1016/j.fct.2011.08.013.

5. P. L. Pérez de Paz and C. E. Hernández Padrón, Plantas Medicinales o Útiles en la Flora Canaria. Aplicaciones Populares, 1st ed., Francisco Lemus Editor Sl, La Laguna 1999.

6. S. Dévora, S. Abdala and D. Martín-Herrera, Peripheral analgesic and anti-inflammatory effects of Smilax canariensis in an animal model, Pharmacol. Pharm. 6 (2015) 391-400; DOI: 10.4236/ pp.2015.68040.

7. S. Abdala, S. Dévora, D. Martín-Herrera and P. Pérez-Paz, Antinociceptive and anti-inflammatory activity of Sambucus palmensis Link, an endemic Canary Island species, J. Ethnopharmacol. 155 (2014) 626-632; DOI: 10.1016/j.jep.2014.06.002.

8. G. F. Pavao-de-Souza, A. C. Zarpelon, G. C. Tedeschi, S. S. Mizokami, J. S. Sanson, T. M. Cunha, S. H. Ferreira, F. Q. Cunha, R. Casagrande and W. A. Verri, Jr., Acetic acid- and phenyl-p-benzoquinone-induced overt pain-like behavior depends on spinal activation of MAP kinases, $\mathrm{PI}_{3} \mathrm{~K}$ and microglia in mice, Pharmacol. Biochem. Behav. 101 (2012) 320-328; DOI: 10.1016/j.pbb.2012.01.018.

9. M. Barrot, Tests and models of nociception and pain in rodents, Neuroscience 211 (2012) 39-50; DOI: 10.1016/j.neuroscience.2011.12.041. 
10. A. Tjolsen, D. G. Berge, S. Hunskaar, J. H. Rosland and K. Hole, The formalin test: an evaluation of the method, Pain 51 (1992) 5-17; DOI: 10.1016/0304-3959(92)90003-T.

11. B. G. Katzung, S. B. Masters and A. J. Trevor, Farmacología Básica y Clínica, 11th ed., McGraw-Hill - Lange, New York 2010; DOI: 10.1036/0071451536.

12. S. M. Thomazzi, C. B. Silva, D. C. R. Silveira, C. I. C. Vasconcellos, A. F. Lira and E. V. F. Cambui, Antinociceptive and anti-inflammatory activities of Bowdichia virgilioides (sucupira), J. Ethnopharmacol. 127 (2010) 451-456; DOI: 10.1016/j.jep.2009.10.014.

13. D. Kashyap, H. S. Tuli and A. K. Sharma, Ursolic acid (UA): A metabolite with promising therapeutic potential, Life Sci. 146 (2016) 201-213; DOI: 10.1016/j.lfs.2016.01.017.

14. J. Higgs, C. Wasowski, L. M. Loscalzo and M. Marder, In vitro binding affinities of a series of flavonoids for $\mu$-opioid receptors. Antinociceptive effect of the synthetic flavonoid 3, 3-dibromoflavanone in mice, Neuropharmacology 72 (2013) 9-19; DOI: 10.1016/j.neuropharm.2013.04.020.

15. S. Fan, N. A. Ali and D. F. Basri, Evaluation of analgesic activity of the methanol extract from the galls of Quercus infectoria (Olivier) in rats, Evid. Based Complement. Alternat. Med. 2014 (2014) 1-6; DOI: 10.1155/2014/976764. 